\title{
An Evaluation of Patron Perceptions of Library Space Using the Role Repertory Grid Procedure
}

\author{
Joy K. Potthoff, David L. Weis, Dale S. Montanelli, and \\ Matthew M. Murbach
}

The evaluation of library space for its effectiveness and efficiency in meeting patron needs is an important part of the process in planning library facilities. However, techniques for obtaining such information are not widely available in the library science literature. The Role Repertory Grid Procedure, a technique derived from personal construct theory in the behavioral sciences, was evaluated for its practicality and validity as a way of gathering patron perceptions about the effectiveness and efficiency of library space. The grid did provide useful information on patrons' perceptions of library space. However, although the Role Repertory Grid Procedure was found to be fairly easy to administer, questions about its validity and reliability remain to be answered. The authors believe that further work to simplify the analysis will be necessary before the grid can be widely used in evaluating library space.

This project was funded in part by the Council on Library Resources, in Washington, D.C.

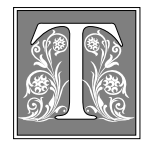

he evaluation of library space for its effectiveness and efficiency in meeting patron needs is an important part of the process in planning library facilities. However, techniques for obtaining such information are not widely available in the library science literature. The Role Repertory Grid Procedure, a technique derived from personal construct theory in the behavioral sciences, was evaluated for its practicality and validity as a way of gathering patron perceptions about the effectiveness and efficiency of library space. The grid did provide useful information on patrons' perceptions of library space. However, although the Role Repertory Grid Procedure was found to be fairly easy to administer, questions about its validity and reliability remain to be answered. The authors believe that further work to simplify the analysis will be

Joy K. Potthoff is an Associate Professor in the School of Family and Consumer Sciences at Bowling Green State University; e-mail: jpottho@bgnet.bgsu.edu. David L. Weis is a Professor in the School of Family and Consumer Sciences at Bowling Green State University: e-mail: weis@bgnet.bgsu.edu. Dale S. Montanelli is an Associate Professor in the Department of Human and Community Development at the University of Illinois at Urbana-Champaign; e-mail: montanel@uiuc.edu. Matthew M. Murbach is a Technical Support Specialist at Software Solutions in Duluth, Georgia; e-mail: mmurbach@sofsol.com. 
necessary before the grid can be widely used in evaluating library space.

The evaluation of library space for its effectiveness and efficiency in meeting patron needs is an important part of the process in planning new, remodeled, or realigned library facilities. Lamar L. Veatch discussed the importance of environmental design in the planning of library space. ${ }^{1}$ He stressed the need for libraries to assess how their environments meet the social, physical, psychological, and behavioral needs of patrons and staff before beginning new construction, renovation, or rearrangement projects. This type of assessment of library environments has become increasingly important as libraries change their activities to meet the needs of both modern technology and patrons. ${ }^{2}$ As the computer terminal replaces the card catalog as the primary access point for information about the collection, the requirements for space, lighting, and even heating and/or airconditioning change. It is only by examining how patrons and staff actually use and view the library facility that historical design errors can be identified (and occasionally corrected) and the impact of technological change on patron needs can be assessed. In truth, such empirical analysis should precede building planning, wherever practical, whether for new or renovated space.

Joy Potthoff and Dale S. Montanelli reviewed research methodologies as tools for library space planning. ${ }^{3}$ Library studies tended to rely on literature reviews, interviews, and questionnaires but rarely used more than one technique or addressed questions about the validity of respondent reports. Studies from social science disciplines, which were mostly of classroom and office environments, also used questionnaires or interviews. However, these studies employed multiple techniques for gathering information and took steps to reduce potential self-report

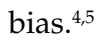

Potthoff and Montanelli concluded that when considering library space problems, librarians need to use a broader range of assessment techniques to determine not only how many square feet are needed for a library function, but also how patrons and staff perceive that space. ${ }^{6}$ Because direct input from library patrons is important, it seems desirable to develop alternative methods of gathering patron input that are not prone to the biases found in typical self-report methodology.

Personal construct theory, originally developed in psychology, has been used successfully to gather perceptual data in areas of urban planning. ${ }^{7}$ Martha S. Wysor investigated attitudes of students toward environmental concerns such as pollution control and recycling. ${ }^{8}$ She compared self-report methods with the perceptual choices of students using the Role Repertory Grid Procedure. More recently, personal construct theory, with the corresponding Role Repertory Grid, was used to study aesthetic judgments about visual art and choice of shopping centers. ${ }^{9,10}$ Each of these researchers reported that the Role Repertory Grid Procedure was an effective tool for assessing individual attitudes.

The procedure was developed by George Kelly as a means of testing his personal construct theory. ${ }^{11}$ Kelley maintained that individuals use mental images of their environment or "personal constructs," which are developed through experience, to guide their behavior. For Kelly, the task for researchers is to get individuals to describe these constructs without the biases inherent in self-reporting.

John Harrison and Philip Sarre, a British geographer and a British social scientist, applied the Role Repertory Grid Procedure to the study of mental images of the physical environment. ${ }^{12}$ Their most famous study was an attempt to measure the general image of the city of Bath held by a group of residents. Harrison and Sarre were interested in the applicability of the methodology, not just the specific outcomes. ${ }^{13}$ Although they focused on environments of a much larger nature (cities), the techniques they employed also may be appropriate for libraries. 
In the present research, the Role Repertory Grid Procedure was tested for its practicality as a way of gathering patron perceptions about library space. The test actually consists of two procedures. In the first, respondents are asked to identify relevant areas in a given space. In the second, they are asked to make forced-choice decisions about the similarity and / or difference of triad groupings of photographs of areas identified in the first procedure, what Kelly called the method of triads. ${ }^{14}$ The triads are composed of three elements (or objects to which judgment is applied). The judgments reflect the personal constructs people use to assess the environment. Some evidence suggests that this procedure of asking respondents to select the photographs that are most similar is equivalent to asking them to indicate a preference. ${ }^{15}$

One component of this study was the gathering of data necessary for a practical solution to an existing space problem in a library at a state university in the Midwest. By using an existing space, the researchers were able to gain substantial information about an actual library environment that is in need of rearrangement and renovation. The library is a part of the university's Architecture Building. Constructed in 1926, it is Georgian revival in style, with tall, arched windows; custom-carved, stained pine woodwork; and plaster friezes on the walls.

Consistent with the Role Repertory Grid Procedure, patron perceptions of space within the library were investigated in two independent studies. Responses from the participants in study 1 were used to construct the triads used in study 2 .

\section{Study 1}

A total of sixty-five respondents, in three separate groups of library patrons at a state university in the Midwest, were asked to respond to a questionnaire concerning their knowledge and impressions of the library space. The groups consisted of twenty-three graduate students in library and information science (LIS), nineteen graduate students from the School of Architecture, and twenty-three undergraduate students studying interior design. All sixty-five students reported that they were familiar with the floor plan of the library, although fourteen (21.5\%) indicated that they had never visited the library before. These three groups of patrons were chosen for this preliminary phase because they were thought to use the library regularly.

\section{Differences between groups ap- peared to occur as a reflection of the way in which the people who study different curricula use the library.}

\section{Questionnaire}

The questionnaire contained a series of eleven questions and a floor plan diagram, drawn to scale, of the library. The first question asked the patrons to circle and label areas on the floor plan that they could identify (e.g., journal area, modern architecture area, circulation desk). A second question asked them if they understood the floor plan. Possible answers were yes and no. The students then were asked to rate a series of seven features of the library on 5-point semantic differential item. The seven features were: (1) spacious/crowded, (2) clean/dirty, (3) neat/ messy, (4) easy-to-locate materials/hardto-locate materials, (5) quiet/noisy, (6) well lit/dimly lit, and (7) comfortable temperature/uncomfortable temperature. The students then were given a group of open-ended questions asking them to name the most important and unimportant areas of the library, the features of the library they most and least liked, and what they regarded as the library's most prominent architectural feature. They also were asked how often they had visited the library previously. And finally, they were asked to identify any other library that had impressed them. The questionnaire took each student about ten minutes to complete.

\section{Results}

1. Areas of Library the Students Could Identify 
Sixty-one of the sixty-five students indicated they could identify twenty-two areas within the library. Areas cited by more than ten students included the main stacks, the periodicals area, the circulation desk, and the study area. In general, there was consistency across the three groups. The circulation desk was identified by approximately three-quarters of all subjects in each group, whereas the stacks and the periodicals area were identified by more than onehalf of each group.

Differences between groups appeared to occur as a reflection of the way in which the people who study different curricula use the library. For example, 63.8 percent of the architecture students identified the reserve area, but few other students did. This may be the result of the architecture class reserves being held in this particular library, whereas LIS and interior design class reserves are held in other libraries in the university system. Likewise, the high level of identification of the reference area by LIS students may be the result of their class assignments requiring use of this particular library.

The fourteen areas that were identified consistently by more than five students in each group were selected for inclusion in study 2 of this project. In addition, study 2 included a ceramic tile mosaic of the library's name.

2. Semantic Differential Items

The students then were asked to rate a series of seven features of the library space, using a 5-point semantic differential format. The means and standard deviations for these seven semantic differentials are presented in table 1.

Overwhelmingly, the students regarded the library as crowded. Although responses were somewhat mixed, as a group, the students felt that the library was slightly dirty and messy and that it was difficult to locate materials. On the other hand, most of the students regarded the library as quiet and well lit.

A principal component factor analysis of these items failed to yield any clear underlying factor structure, showing that responses to these various features of the library were relatively independent (responses to any given item were not strongly correlated with responses to the others). Moreover, tests of internal consistency (Cronbach's alpha) also showed that the responses were relatively uncorrelated. A few individual comparisons were exceptions and are worth noting. Perceptions that the library is clean were correlated with perceptions that the library is neat $(\mathrm{r}=.48, \mathrm{p}<.01)$. Perceptions that the library is quiet were correlated with perceptions that it is well lit ( $\mathrm{r}$ $=.32, \mathrm{p}<.01$ ), and perceptions that the library is well lit were correlated with perceptions that it has a comfortable temperature $(\mathrm{r}=.38, \mathrm{p}<.01)$.

3. Most Important Area

\begin{tabular}{|lcc|}
\hline \multicolumn{3}{|c|}{ TABLE 1 } \\
Library Patrons Perceptions of Features of Library & Space \\
\hline \hline Feature & Mean* & SD \\
\hline Crowded/spacious & 1.78 & 0.86 \\
Dirty/clean & 2.83 & 0.95 \\
Messy/neat & 2.72 & 1.02 \\
Hard to locate materials/easy to locate materials & 2.69 & 1.12 \\
Noisy/quiet & 3.12 & 1.16 \\
Dimly lit/well lit & 3.75 & 0.91 \\
Uncomfortable temperature/comfortable temperature & 3.60 & 0.93 \\
& & \\
Note: Individual items were scored on a five-point scale, ranging from 1, negative quality, to 5, \\
positive quality.
\end{tabular}


In response to the question about which feature of the library the students considered most important (six missing), nine areas were identified. More than ten persons named the periodical area and the study area. Five to nine students cited the main stacks, the circulation area, and the reference area.

\section{Least Important Area}

No area of the library was mentioned by more than ten persons in response to a question about which area was least important (seventeen missing). The study area, the vertical files, and the folios area were mentioned by five to nine persons as the least important library feature. Students identified a total of eighteen areas in response to this question.

5. Feature Liked Most

Respondents also were asked which feature of the library they liked most (nine missing). Nineteen areas were named. The entrance, the study area, the woodwork, and the lighting were cited by five to nine persons; no feature was mentioned by more than ten persons.

6. Feature Liked Least

In response to the item asking students to name the feature of the library they liked least (seven missing), sixteen areas were identified. Five to nine persons mentioned lighting and noise, and more than ten persons noted that the library was crowded and poorly organized.

7. Architectural Feature Liked Most When students were asked to name the architectural feature they liked the most (two missing), they named a total of ten features. Five to nine persons cited the windows, and more than ten students named the entrance and the woodwork.

8. Most Prominent Architectural Feature

In response to a question asking students to name the library's most prominent architectural feature (nine missing), the students named a total of eleven features. Five to nine persons cited the windows and the woodwork, and thirty-three students $(58.9 \%)$ named the entrance. The mention of the entrance as the most prominent architectural feature was, by far, the most common response to this entire series of open-ended questions about the library.

9. Number of Visits to Library The students then were asked to indicate how often they had visited the library. A summary of their responses is presented in table 2. Although a majority reported that they had visited the library more than ten times, it is worth noting that a sizable group $(21.5 \%)$ reported that they had never been to this library. The number of visits students had made to the library was significantly correlated with a number of ratings of library features. Those students who reported having visited the library more frequently were more likely to rate it as difficult to locate materials $(\mathrm{r}=$ $-.28, \mathrm{p}<.05)$, dimly lit $(\mathrm{r}=-.30, \mathrm{p}<.05)$, and having an uncomfortable temperature $(\mathrm{r}=-.33, \mathrm{p}<.01)$.

10. Impressed by Other Libraries

Finally, the students were asked if they had ever visited another library that had impressed them. Forty-seven $(77.0 \%)$ responded yes. The responses to this item were not significantly correlated with any of the perceptual ratings of the library features.

\section{Discussion for Study 1}

The first study was designed to ask a group of students to evaluate the library using fairly standard questionnaire items and to identify areas of the library for in-

\begin{tabular}{|c|c|c|}
\hline \multicolumn{3}{|c|}{$\begin{array}{l}\text { TABLE } 2 \\
\text { Frequency of Student Visits to the } \\
\text { Architecture Library }(\mathrm{N}=65)\end{array}$} \\
\hline No. of Visits & $\begin{array}{c}\text { No. of } \\
\text { Respondents }\end{array}$ & $\%$ \\
\hline None & 14 & 21.5 \\
\hline One time & 7 & 10.8 \\
\hline $3-5$ times & 2 & 3.1 \\
\hline 8-9 times & 8 & 12.3 \\
\hline More than 10 times & 34 & 52.3 \\
\hline \multicolumn{3}{|c|}{$\begin{array}{l}\text { Note: The above categories were in response to } \\
\text { an item asking respondents to indicate the } \\
\text { number of times they had visited the library. }\end{array}$} \\
\hline
\end{tabular}


clusion in the Role Repertory Grid Procedure to be used in study 2. Many of the students participating in study 1 indicated that they were familiar with several areas of the library. Differences in the areas cited by students seemed to be associated with their major area of study. A total of fourteen library areas were identified by the students for inclusion in the procedure in study 2 .

Although the library was a positive feature for a large group of the students, a sizable minority had negative feelings about it. Clearly, the outstanding features were the entrance, the woodwork, and the windows. In general, most of the students found the library to be well lit and quiet, but also crowded, dirty, and messy. Attempts to develop a single scale for these various evaluations of the library space failed, indicating that these assessments were independent of each other. Interestingly, the more frequently students used the library, the more likely they were to evaluate it negatively.

\section{Study 2}

In study 2, a short questionnaire and an interview were given to an independent group of forty patrons of the library. A research confederate approached persons who were in the library and asked if they would be willing to participate. Those who agreed were escorted to a table, where they were seated and asked to indicate their staff or student status at the university, their academic department or major, and their gender. They also were asked how often they used the library facilities. Of the forty who completed the survey, thirty were undergraduates, three were graduate students, six were staff members, and one was a faculty member of the university. The overwhelming majority of these patrons $(n=28,70 \%)$ were majors in or members of the architecture program. However, the sample also included majors in anthropology, architecture and history, art history, electrical engineering, interior design, and the library staff. Twenty of these respondents were male, and twenty were female. Thirteen $(32.5 \%)$ reported daily use of the library, twenty-two (55\%) reported weekly use, two $(5 \%)$ reported bimonthly use, two (5\%) reported monthly use, and one $(2.5 \%)$ reported using the library rarely.

\section{Role Repertory Grid Procedure (Method of Triads)}

The fourteen areas of the library most frequently named by the study 1 participants as areas they could identify were selected for inclusion in study 2 . In addition, study 2 included a ceramic tile mosaic of the library's name. Each of these areas was then photographed and the photographs numbered, and the identifying numbers were randomly selected without replacement to produce five sets of three pictures each. This sampling was done three times to create a total of fifteen triads of photographs. Participants were asked to indicate which two pictures in each triad were most similar and why, and which two were most different and why, a procedure that has been found to generate useful judgment data. ${ }^{16}$ The interviewer recorded the choices for each triad and the exact phrases used to explain the choices on a specifically prepared report sheet. Each participant required an average of thirty minutes to complete the interview.

The reasons given for the selection of similar and different pictures were subjected to a form of content analysis known as thematic analysis. ${ }^{17,18}$ Following procedures established by Timothy Perper and David L. Weis, the researchers identified all the themes given by respondents as reasons for choosing the photographic pairings they did. ${ }^{19}$ All responses were read several times, first to identify themes and later to obtain theme frequencies. Every reason given was either assigned a theme or recognized as unique. For a reason to be identified as a theme, it had to be explicitly named by at least two respondents. By definition, the themes are comments made explicitly and overtly by the respondents. No implicit categories developed by the presuppositions of the researchers were coded as a theme. Thus, 
the respondents were able to express their own thoughts rather than having their thoughts interpreted by the researchers. Moreover, this approach allowed multiple themes to be identified for any particular respondent. In fact, many respondents gave more than one reason for making a particular choice. This ranged from a low of one theme to a high of seven.

After several readings to develop a complete catalog of themes, the researchers made a final calculation of theme frequencies (which represents the percentage of respondents mentioning each theme). This coding was performed by two of the researchers who initially agreed on 96.8 percent of the similarity codings and 94.3 percent of the difference codings. Because, by definition, a theme had to be stated explicitly in order to be counted, ambiguous statements failed to meet the criteria. No formal measures of interrater reliability were calculated because such measures presuppose independent ratings of a priori categories. In this study, the researchers worked together to develop the theme categories. Only those statements the researchers agreed had been made explicitly were coded as themes. It will remain for a future researcher to use this system to address the question of interrater reliability among independent judges.

\section{Results}

Explanations of the reasons for choosing particular pairs of photographs as similar or different ranged from brief, terse comments to highly detailed, elaborate analyses. Ultimately, the researchers identified and coded a total of ten themes:

0 . Do not use library: The respondent explicitly stated that he or she did not use the library. Although this might imply that no other themes would be mentioned, some respondents did proceed to offer further reasons for the choices they had made.

1. Learning materials: The respondent explicitly stated that books, folios, shelves, or other learning materials were either similar or different.
2. Space concerns: The respondent explicitly described the space in the photographs as messy, neat, open, closed, proximal, cluttered, confined, accessible, organized, or the like.

3. Architecture: The respondent cited architectural features as similar or different in the photographs, such as windows, doors, arches, woodwork, or metal, or described the library as new or old.

4. Lighting: The respondent explicitly mentioned lights or lighting, or described an area as bright, dark, well lit, or poorly lit.

5. Furniture: The respondent explicitly cited furniture such as chairs, tables, or computers as the basis for concluding that photographs were similar or different.

6. Acoustics: The respondent explicitly described an area as noisy or quiet.

7. People: The respondent explicitly mentioned people, crowds, or social activities, or described the area as busy or lonely.

8. Aesthetics: The respondent explicitly described the aesthetics or beauty of the area using words such as ugly, pretty, colorful, good view, casual, formal, or inviting.

9. Function: The respondent chose photographs as similar or different because of the ways people used the space or because of the functions the space served. Examples included statements about using an area, doing something in the area, looking up information, studying in the area, not using the area much, and stating that it was difficult to use the area. This theme also was coded if the respondent stated that he or she sat or walked in the area.

For most of the photograph triads, the same pair was picked as similar by most respondents, and the reasons for similarity, although expressed differently, tended to focus on the same concept, such as learning materials or the architecture of the space. There appeared to be less consistency in the selection of photograph pairs as different. In some cases, the pair in each triad that was selected as most 
similar also was selected as most different. A review of the theme frequencies for similarities and differences showed that the principle themes were learning materials, architecture, and function. Themes that were mentioned by few respondents included do not use, space concerns, lighting, furniture, acoustics, people, and aesthetics. Because of the relatively small sample and the large number of potential cells, the only themes included in subsequent chi-square analyses were learning materials, architecture, and function. A summary of those analyses is presented in tables 3 and 4 .

The Role Repertory Grid Procedure did yield useful information about the universe of themes that library patrons use in making judgments about library space.

The results displayed in tables 3 and 4 establish that a large number of the respondents $(n>20, \%>50)$ used the learning materials, architecture, or function themes to explain their choices of which photographs in the fifteen triads were similar or different. The tables suggest that there was greater uniformity in response to the similarity reasons than the difference reasons, but these three themes dominated both sets of responses. The tables also indicate that there were some significant differences in the reasons provided for similarity and difference choices. Six of the similarity comparisons yielded significant differences, but only two of the difference comparisons were significant $(\mathrm{p}<.01)$. This alpha level was chosen because of the large number of tests conducted to reduce the probability of type-I errors. Unfortunately, there did not appear to be any clear underlying pattern to those differences in the series of $3 \times 3$ tables.

Subsequent chi-square analyses indicated that there were no significant differences ( $p$ > .01) between males and females; among faculty, staff, graduate students, or undergraduate students; or varying frequencies of library use in the making of similarity and difference judgments.

\section{Discussion for Study 2}

Study 2 was designed to test the usefulness of the Role Repertory Grid Procedure, a methodological approach developed to offset many of the problems associated with standard self-report methods used in the evaluation of space. The procedure did prove to be easy to administer. Respondents were readily able to make choices about which of fifteen triads of photographs were most similar and most different, and they were able to provide reasons for the choices they made. Moreover, the Role Repertory Grid Procedure and the thematic analysis employed in this research to analyze responses seemed to be a valuable way to identify the entire spectrum of possible responses. The researchers' analysis of themes that were relevant to the respondents' assessments of the library space did not impose arbitrary factors on the persons participating in the research. Rather, this method allowed respondents to speak for themselves.

This thematic analysis succeeded in identifying ten themes that respondents cited for the judgments they made. The most prominent of these were learning materials, architecture, and function. Some respondents mentioned other themes, but these were less common. Additional research on the reliability and validity of this set of themes will be necessary. On the other hand, this approach also seemed to possess several limitations. The thematic analysis was time-consuming and highly complex, perhaps too complex for many librarians to use. In addition, the small sample used in this research prevented a more systematic statistical analysis of the less frequently cited themes.

\section{General Discussion}

The present research was developed on the premise that assessment of patron perceptions is an important component of plans for the utilization and design of library space. This project attempted to test a new approach, the Role Repertory Grid Procedure, to collecting data on patron 
TABLE 3

Frequency of the Use of the Learning Materials, Architecture, and Function Themes Cited in Similarity Judgments, with Corresponding Chi-square Analyses

\begin{tabular}{|c|c|c|c|c|c|c|}
\hline Set & Pair Selected as Similar & $\begin{array}{l}\text { Learning } \\
\text { Materials }\end{array}$ & Architecture & Function & $\mathbf{X}^{2}$ & $\mathbf{p}$ \\
\hline 1 & Bound journals/stacks & 0 & 2 & 0 & & \\
\hline \multirow[t]{2}{*}{$(005)$} & Bound journals/picture files & 0 & 2 & 0 & 23.71 & $.0000 *$ \\
\hline & Stacks/picture files & 1 & 21 & 0 & & \\
\hline 2 & Reserves/card catalog & 0 & 7 & 1 & & \\
\hline \multirow[t]{2}{*}{$(007)$} & Reserves/circulation & 0 & 0 & 2 & 23.47 & $.0000 *$ \\
\hline & Card catalog/circulation & 13 & 2 & 2 & & \\
\hline 3 & Periodicals/online catalog & 4 & 1 & 8 & & \\
\hline \multirow[t]{2}{*}{$(009)$} & Periodicals/circulation & 0 & 0 & 1 & 7.13 & .1291 \\
\hline & Online catalog/circulation & 1 & 6 & 5 & & \\
\hline 4 & Vault/entrance & 23 & 0 & 3 & & \\
\hline \multirow[t]{2}{*}{$(011)$} & Vault/window folios & 3 & 0 & 0 & 33.44 & $.0000 *$ \\
\hline & Entrance/window folios & 0 & 4 & 0 & & \\
\hline 5 & Mosaic/study table & 1 & 1 & 4 & & \\
\hline \multirow[t]{2}{*}{$(013)$} & Mosaic/copier & 4 & 2 & 1 & 12.60 & .0124 \\
\hline & Study table/copier & 1 & 0 & 12 & & \\
\hline 6 & Reserves/stacks & 0 & 2 & 1 & & \\
\hline \multirow[t]{2}{*}{$(015)$} & Reserves/circulation & 1 & 0 & 2 & 11.65 & .0202 \\
\hline & Stacks/circulation & 13 & 2 & 2 & & \\
\hline 7 & Window folios/journals & 5 & 18 & 7 & & \\
\hline \multirow[t]{2}{*}{$(017)$} & Window folios/vault & 1 & 0 & 1 & 5.62 & .2292 \\
\hline & Journals/vault & 0 & 0 & 1 & & \\
\hline 8 & Study table/picture files & 4 & 1 & 2 & & \\
\hline \multirow[t]{2}{*}{$(019)$} & Study table/arch. ref. & 0 & 4 & 3 & 8.65 & .0704 \\
\hline & Picture files/arch. ref. & 1 & 4 & 5 & & \\
\hline 9 & Copier/card catalog & 0 & 2 & 0 & & \\
\hline \multirow[t]{2}{*}{$(021)$} & Copier/periodicals & 0 & 24 & 0 & 27.00 & $.0000 *$ \\
\hline & Card catalog/periodicals & 0 & 0 & 1 & & \\
\hline 10 & Entrance/online catalog & 1 & 1 & 6 & & \\
\hline \multirow[t]{2}{*}{$(023)$} & Entrance/mosaic & 8 & 2 & 2 & 15.68 & $.0035^{*}$ \\
\hline & Online catalog/mosaic & 0 & 4 & 2 & & \\
\hline 11 & Periodicals/picture files & 7 & 9 & 1 & & \\
\hline \multirow[t]{2}{*}{$(025)$} & Periodicals/circulation & 6 & 1 & 0 & 6.66 & .0904 \\
\hline & Picture files/circulation & 1 & 2 & 1 & & \\
\hline 12 & Entrance/online catalog & 8 & 1 & 6 & & \\
\hline \multirow[t]{2}{*}{$(027)$} & Entrance/window folios & 3 & 2 & 0 & 4.81 & .0904 \\
\hline & Online catalog/window folios & 0 & 0 & 0 & & \\
\hline 13 & Vault/reserves & 1 & 3 & 3 & & \\
\hline \multirow[t]{2}{*}{$(029)$} & Vault/card catalog & 3 & 3 & 1 & 2.08 & .7213 \\
\hline & Reserves/card catalog & 4 & 7 & 5 & & \\
\hline 14 & Copier/circulation & 1 & 1 & 1 & & \\
\hline \multirow[t]{2}{*}{$(031)$} & Copier/bound periodicals & 2 & 12 & 1 & 15.34 & $.0040 *$ \\
\hline & Circulation/bound periodicals & 0 & 0 & 4 & & \\
\hline \multirow{3}{*}{$\begin{array}{l}15 \\
(033)\end{array}$} & Mosaic/study table & 0 & 5 & 0 & & \\
\hline & Mosaic/stacks & 1 & 14 & 0 & 0.35 & .5536 \\
\hline & Study table/stacks & 0 & 0 & 0 & & \\
\hline
\end{tabular}




\begin{tabular}{|c|c|c|c|c|c|c|}
\hline & $\begin{array}{r}\text { Frequency of the Use of } \\
\text { and Function Themes } \\
\text { Corresponc }\end{array}$ & $\begin{array}{r}\text { TABL } \\
\text { f the Lear } \\
\text { s Cited in } \\
\text { nding Chi }\end{array}$ & $\begin{array}{l}\mathbf{E} 4 \\
\text { rning Materi } \\
\text { Difference J } \\
\text {-square Ana }\end{array}$ & $\begin{array}{l}\text { als, Arch } \\
\text { udgment } \\
\text { lyses }\end{array}$ & $\begin{array}{l}\text { itecture } \\
\text {, with } \\
\end{array}$ & \\
\hline Set & Pair Selected as Similar & $\begin{array}{l}\text { Learning } \\
\text { Materials }\end{array}$ & Architecture & Function & $\mathbf{X}^{2}$ & $\mathbf{p}$ \\
\hline 1 & Bound journals/stacks & 4 & 8 & 1 & & \\
\hline$(035)$ & Bound journals/picture files & 0 & 2 & 0 & 3.45 & .4861 \\
\hline & Stacks/picture files & 1 & 0 & 0 & & \\
\hline 2 & Reserves/card catalog & 0 & 5 & 0 & & \\
\hline$(038)$ & Reserves/circulation & 2 & 10 & 2 & 4.09 & .3935 \\
\hline & Card catalog/circulation & 0 & 1 & 1 & & \\
\hline 3 & Periodicals/online catalog & 1 & 4 & 1 & & \\
\hline$(041)$ & Periodicals/circulation & 0 & 1 & 7 & 10.49 & .0330 \\
\hline & Online catalog/circulation & 0 & 0 & 4 & & \\
\hline 4 & Vault/entrance & 1 & 0 & 0 & & \\
\hline (044) & Vault/window folios & 2 & 12 & 4 & 4.26 & .3723 \\
\hline & Entrance/window folios & 3 & 3 & 1 & & \\
\hline 5 & Mosaic/study table & 2 & 0 & 3 & & \\
\hline$(047)$ & Mosaic/copier & 0 & 1 & 8 & 9.13 & .0580 \\
\hline & Study table/copier & 2 & 4 & 3 & & \\
\hline 6 & Reserves/stacks & 0 & 4 & 3 & & \\
\hline$(050)$ & Reserves/circulation & 3 & 14 & 0 & 15.63 & $.0036^{*}$ \\
\hline & Stacks/circulation & 0 & 0 & 2 & & \\
\hline 7 & Window folios/journals & 0 & 0 & 0 & & \\
\hline$(053)$ & Window folios/vault & 1 & 2 & 5 & 3.27 & .1947 \\
\hline & Journals/vault & 3 & 7 & 3 & & \\
\hline 8 & Study table/picture files & 0 & 1 & 7 & & \\
\hline$(056)$ & Study table/arch. ref. & 0 & 2 & 3 & 12.38 & $.0147 *$ \\
\hline & Picture files/arch. ref. & 2 & 1 & 0 & & \\
\hline 9 & Copier/card catalog & 0 & 12 & 3 & & \\
\hline$(059)$ & Copier/periodicals & 0 & 0 & 0 & 0.95 & .8297 \\
\hline & Card catalog/periodicals & 0 & 4 & 0 & & \\
\hline 10 & Entrance/online catalog & 1 & 3 & 4 & & \\
\hline$(062)$ & Entrance/mosaic & 1 & 2 & 3 & 0.88 & .9281 \\
\hline & Online catalog/mosaic & 0 & 2 & 3 & & \\
\hline 11 & Periodicals/picture files & 0 & 0 & 0 & & \\
\hline$(065)$ & Periodicals/circulation & 1 & 3 & 0 & 0.28 & .5967 \\
\hline & Picture files/circulation & 4 & 6 & 0 & & \\
\hline 12 & Entrance/online catalog & 0 & 0 & 1 & & \\
\hline$(068)$ & Entrance/window folios & 1 & 1 & 2 & 5.31 & .2574 \\
\hline & Online catalog/window folios & 0 & 7 & 4 & & \\
\hline 13 & Vault/reserves & 0 & 4 & 4 & & \\
\hline$(071)$ & Vault/card catalog & 0 & 5 & 3 & 0.73 & .6930 \\
\hline & Reserves/card catalog & 0 & 5 & 2 & & \\
\hline 14 & Copier/circulation & 1 & 3 & 3 & & \\
\hline (074) & Copier/bound periodicals & 0 & 1 & 2 & 2.02 & .7320 \\
\hline & Circulation/bound periodicals & 2 & 4 & 2 & & \\
\hline 15 & Mosaic/study table & 0 & 6 & 3 & & \\
\hline$(077)$ & Mosaic/stacks & 1 & 1 & 0 & 13.54 & $.0089 *$ \\
\hline & Study table/stacks & 0 & 9 & 0 & & \\
\hline
\end{tabular}


perceptions and to compare this approach to more standard self-report questionnaire methods. The preliminary step of asking library patrons to identify areas of the library they knew seemed to be an effective device for constructing the set of fifteen photograph triads used in study 2. The Role Repertory Grid Procedure did yield useful information about the universe of themes that library patrons use in making judgments about library space. Additional research is needed to determine the validity and reliability of this approach, whether the themes identified in this project can be used in a priori analyses of library space, and whether the Role Repertory Grid Procedure can be converted into a more statistically usable and "librarian-friendly" format.

However, the results of study 1 and study 2 also illustrate the importance of developing such a methodological approach in the study of patron perceptions of library space. The typical evaluation items in study 1 indicated that students found the library to be messy and dirty (space concerns), well lit (lighting), quiet (acoustics), and crowded (people). Although these themes were identified in the Role Repertory Grid Procedure in study 2 , they were not prominent or com- mon reasons given for the similarity or difference choices made. Instead, the themes of learning materials, architecture, and function emerged as most prominent. This suggests that direct, self-report questioning and less overt decision-making methodologies may yield divergent results, a finding that may have great relevance for the design of building spaces in general. As just one example, it raises questions about which themes or factors people actually use in making judgments about space. Perhaps a lens model methodology could be used to determine such social judgments. ${ }^{20}$

Ultimately, the researchers were concerned about perceptions of space in the library in order to improve the efficiency and effectiveness of the delivery of library services. This research demonstrated that different methodological approaches do seem to yield different sets of results. The project also has identified a number of problems, in both the library itself and the methodological tools available to researchers. Although numerous questions remain about how to assess patron needs and perceptions accurately, the results do provide a challenge to develop more sophisticated and more accurate assessment tools.

\section{Notes}

1. Lamar L. Veatch, "Toward the Environmental Design of Library Buildings," Library Trends 36, no. 2 (1987): 361-76.

2. Michael C. Matier and C. Clinton Sidle, "Developing a Strategic Plan for Library Space Needs through 2010" (paper presented at the Annual Spring Conference of the Society for College and University Planning, Philadelphia, Apr. 8-10, 1992).

3. Joy Potthoff and Dale S. Montanelli, "Use of Library Facilities: Behavioral Research as a Tool for Library Space Planning," Journal of Library Administration 12, no. 1 (1990): 47-61.

4. James S. Kidston, "The Validity of Questionnaire Responses," Library Quarterly 55 (Apr. 1985): 133-50.

5. Bernard S. Phillips, Social Research: Strategy and Tactics (New York: Macmillan, 1971).

6. Potthoff and Montanelli, "Use of Library Facilities," 58.

7. George A. Kelly, A Theory of Personality (New York: W. W. Norton, 1963).

8. Martha S. Wysor, “Comparing College Students' Environmental Perceptions and Attitudes: A Methodological Investigation," Environment and Behavior 5, no. 5 (1983): 615-45.

9. Rosamund Joyce Osbourn, "The Aesthetic Response: An Application of Personal Construct Theory to the Perception and Appraisal of Visual Art" (master's thesis, Univ. of Exeter, Dorset, Eng., 1988).

10. Harry Timmermans, Rob Van Der Heiden, and Hans Westerveld, "The Identification of Factors Influencing Destination Choice: An Application of the Repertory Grid Methodology," Transportation 11 (1982): 189-203.

11. Kelly, A Theory of Personality. 
12. John Harrison and Philip Sarre, "Personal Construct Theory in the Measurement of Environmental Images: Problems and Methods," Environment and Behavior 3, no. 4 (Dec. 1971): 251374.

13. _— "Personal Construct Theory in the Measurement of Environmental Images," Environment and Behavior 7, no. 1 (Mar. 1975): 3-58.

14. Kelly, A Theory of Personality.

15. Timbermans, Van Der Heiden, and Westerveld, “The Identification of Factors Influencing Destination Choice," 193.

16. Ibid., 196.

17. Bernard Berelson, Content Analysis in Communication Research (Glencoe, Ill.: Free Pr., 1952).

18. Thomas F. Carney. Content Analysis: A Technique for Systematic Inference from Communications (Winnipeg, Can.: Univ. of Manitoba Pr., 1972).

19. Timothy Perper and David L. Weis, "Proceptive and Rejective Strategies of U.S. and Canadian College Women," Journal of Sex Research 23 (Nov. 1987): 455-80.

20. Ray W. Cooksey, Judgment Analysis: Theory, Methods, and Application (San Diego, Calif.: Academic Pr., 1996). 